\title{
Comparison of ivabradine and metoprolol tartrate impact on the heart rate variability in patients with angina pectoris
}

Naufal Shamilevich Zagidullin*, Rustem Halitovich Zulkarneev, Ekaterina Olegovna Travnikova and Shamil Zarifovich Zagidullin

*Correspondence: znaufal@mail.ru

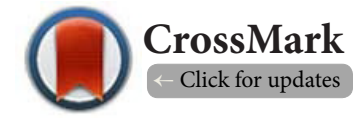

Department of Internal Medicine, Bashkir state Medical University, Russian Federation.

\begin{abstract}
Background: Heart rate variability (HRV) is an effective way to estimate heart rate (HR) autonomic regulation. In some cardiovascular diseases increased sympathetic activity (low frequency spectral power of HRV) was shown to be an unfavorable risk factor which could be downregulated by beta-blockers. There are only few data on I-blocker ivabradine impact on HRV parameters and direct comparison between betablockers and ivabradine in relation to HRV was not conducted. The purpose of the study was to compare the impact of $\mathrm{I}_{\mathrm{f}}$-blocker ivabradine and metoprolol tartrate on autonomic control of nervous system HR control in patients with stable angina pectoris.
\end{abstract}

Methods: Effects of ivabradine $7.5 \mathrm{mg}$ and $50 \mathrm{mg}$ metoprolol tartrate HRV were estimated in 33 patients with angina pectoris in the open-labeled randomized, controlled, crossover design and acute pharmacological test study. HRV was determined for 10 minutes in supine position before and after $4 \mathrm{~h}$ the each test drug according to randomization.

Results: Equal negative chronotropic impact for ivabradine and metoprolol was shown, the effect increased with HR upraise and was positively correlated with baseline HR. Both ivabradine and metoprolol produced downregulating effect of sympathetic tone, but the effect of ivabradine was more significant. However, metoprolol decreased the total power parameter and the value of adaptation.

Conclusions: In patients with angina pectoris $\mathrm{I}_{\mathrm{f}}$-blocker ivabradine downregulation of sympathetic status in comparison with beta-blocker metoprolol tartrate effect was firstly shown.

Keywords: Heart rate variability, ivabradine, metoprolol, CHD

\section{Introduction}

Heart rate variability (HRV) is accessible, informative and efficient way to estimate the balance of sympathetic and parasympathetic nervous system of the heart [1]. Some HRV parameters correlate with the frequency of unfavorable cardiovascular events $[2,3]$ and are used to assess the patients' state, to predict outcomes and to optimize therapy [4]. Coronary heart disease (CHD), especially after myocardial infarction (MI), results in sympathetic and parasympathetic nervous systems heart rate (HR) regulation and correspondingly, HRV imbalance caused by upregulation of low-frequency (LF) and downregulation of high frequency (HF) domain decreases [5]. Therefore, in CHD, especially after MI, the drugs positively affecting HRV are more favorable [2]. Several cardiovascular drugs such as beta-blockers (BB), angiotensin- converting enzyme inhibitors and angiotensin receptor blockers have proved to modulate HRV [4]. The classical ones are BBs, which not only reduce the $\mathrm{HR}$, but also normalize the above mentioned balance of sympathetic/parasympathetic system of $\mathrm{HR}$ regulation by upregulating $\mathrm{HF}$ and, on the contrary, by downreguling LF and very LF components [6-8].

Ivabradine is a unique drug from the group of $\mathrm{I}_{\mathrm{f}}$-blockers, selectively decreasing HR $[\mathbf{9}, \mathbf{1 0}]$. According to the guidelines, it could be used in stable angina pectoris and chronic heart failure in patients with high $\mathrm{HR}$ especially in case of BB contraindications and lack of BB efficacy, also in combination with the last one [11]. Actual absence of clinical efficacy in non-heart failure patients with CHD in SIGNIFY (Study assessInG the morbidity-mortality beNefits of the If inhibitor ivabradine in 
Zagidullin et al. Cardiovascular System 2014,

patients with coronary artery disease) study [12] and on the contrary, positive effect of ivabradine on the cardiovascular end-points in BEAUTIFUL (MorBidity-mortality EvAlUaTion on the $\mathrm{I}_{\mathrm{f}}$ Inhibitor ivabradine in patients with coronary disease and left ventricULar dysfunction) [13] and SHIFT [14] studies require further clarification. Over the past years the data on ivabradine impact on HRV appeared. Belal et al., (2013) [15] in the small study involving 15 volunteers showed that ivabradine could promote earlier onset and more significant modulation of neural control of cardiovascular system. However, until now no contrastive comparisons of $\mathrm{BB}$ and $\mathrm{I}_{\mathrm{f}}$-blockers impact on HRV have been shown. Joanides et al., (2006) [16] compared the effects of ivabradine and nonselective BB propranalol on the various hemodynamic parameters, including autonomic regulation of cardiovascular system, in 10 healthy volunteers. It was shown that both Iva and propranolol increased HF component as well as HF/LF ratio. However, from the clinical point of view the small number of patients and healthy volunteers but not CHD participants restricted the value of study.

In the present paper the direct comparison of $\mathrm{BB}$ and Ifblocker on cardiac autonomic status in patients with CHD was performed. The purpose of the study was to compare the effects of $\mathrm{I}_{\mathrm{f}}$-blocker ivabradine with BB metoprolol tartrate on HRV in patients with stable angina pectoris in the openlabeled randomized controlled trial with crossover design and acute pharmacological test.

\section{Methods}

33 patients with $\mathrm{CHD}$ and angina pectoris in stable state and good BB compliance participated in the study.

\section{Inclusion criteria}

- Written informed consent

- Stable angina pectoris

- Stable dose of BB before the study

- Body mass index $19-30 \mathrm{~kg} / \mathrm{m}^{2}$

\section{Exclusion criteria}

- Arterial hypotension with systolic BP $<90 \mathrm{~mm} \mathrm{Hg}$

- Acute coronary syndrome

- $\mathrm{HR}<60$ and $>90$ beats/min before the study

- NYHA IV

- Diabetes mellitus

- Atrial fibrillation, atrial flutter, AV-block of II-III degree

- Actual comorbidities

- Myocardial infarction in the past

- Fever, sepsis, myocarditis

\section{Comparators}

I--blocker ivabradine $7.5 \mathrm{mg}$ (Procoralan, Servier, France) and BB metoprolol tartrate $50 \mathrm{mg}$ (Egilok, "Gedeon Richter", Hungary) were chosen for comparison. Both drugs have comparable half-life (12 hours) and the peak of serum concentration (3-4h).
The doses were chosen to decrease heart rate equipotentially.

\section{Study design}

Prospective, open-labeled, short-term, controlled, crossover and acute pharmacological test design has been applied. After obtaining the written informed consent, physical examination (height, weight), auscultation, heart rate, systolic and diastolic blood pressure (SBP and DBP) were estimated. After enrolling in the study patients discontinued using BB for 2 days (washout period) but continued taking other cardiovascular drugs. HRV was estimated in supine position for 10 minutes with "Sphygmacor" (AtCor, Australia) device, and then the patients were randomized. Every patient has equal probability $1 / 2$ to be included in two groups according to software based random number generator. According to the randomization, participants received ivabradine $7.5 \mathrm{mg}$ (group 1) or metoprolol $50 \mathrm{mg}$ (group 2) once per os. In 3.5$4 \mathrm{~h}$, at the peak of drug concentration in serum, patients' HRV was re-estimated (Investigation 2). At least after 2 days the "crossover" test was performed in which the patients previously received $50 \mathrm{mg}$ of metoprolol (Group 2), then they were given ivabradine $7.5 \mathrm{mg}$ and vice-versa. Investigations 3 and 4 were conducted similar to the $1^{\text {st }}$ and the $2^{\text {nd }}$ ones (Figure 1).



Figure 1. Study design (Met-metoprolol tartrat, Iva-ivabradine). Star sign-investigation point.

During the analysis the following HRV indicators were calculated: standard deviation of all R-R intervals-SDNN; square root of the mean squared differences of successive normal NN intervals-RMSSD; LF (low frequency), HF (high frequency) wave spectrums, the total power (TP) and the ratio of low and high frequency waves-LF/HF.

No side and adverse effects (bradycardia, sinus tachycardia, arrhythmias, collapse, etc.) were identified during the research.

Differences between the groups were assessed with Student's t-test for paired variables and the nonparametric Wilcoxon signed-rank test. A value of $p<0.05$ was considered to be significant.

Local bioethical committee of Bashkir State Medical University approved the study.

\section{Results}

33 ambulatory patients ( 16 men and 17 women, aged $56-75$ years) 
with CHD and current diagnosis "angina pectoris" in sinus rhythm and NYHA I-III and without myocardial infarction in the past were enrolled in the study. All the patients signed informed consent. In the Table 1 the basic features of the study group are presented.

Table 1. Characteristics of the patients.

\begin{tabular}{ll}
\hline Parameters & Values \\
\hline $\mathrm{N}$ & 33 \\
$\mathrm{M} / \mathrm{W}$ & $16 / 17$ \\
Age, years & $64.9 \pm 0.94$ \\
Weight, kg & $74.3 \pm 1.7$ \\
Height, cm & $168.8 \pm 0.64$ \\
BMI, kg/m ${ }^{2}$ & $26.08 \pm 1.14$ \\
\hline NYHA function class: & \\
\hline I & 11 \\
II & 20 \\
III & 2 \\
\hline
\end{tabular}

The patients were randomized to receive firstly ivabradine (group 1, 16 patients) and metoprolol (group 2, 17 patients) firstly. Table 2 presents the baseline vital (HR, SBP, DBP) and HRV parameters before the first investigation (pre-dose). No significant difference was found between the groups at the baseline.

Table 2. Baseline vital and HRV parameters in groups 1 and 2.

\begin{tabular}{l|lll}
\hline Parameters & \multicolumn{3}{|c}{ Groups } \\
\cline { 2 - 4 } & All, n=33 & $\begin{array}{l}\text { Ivabradine } \\
\text { (group 1), n=16 }\end{array}$ & $\begin{array}{l}\text { Metoprolol } \\
\text { (group 2), n=17 }\end{array}$ \\
\hline SBP, mm Hg & $132.9 \pm 1.9$ & $133 \pm 3.4$ & $131.3 \pm 2.5$ \\
DBP, mm Hg & $84.8 \pm 1.3$ & $84.6 \pm 2.4$ & ó84 \pm 1.6 \\
HR, beat/min & $73.4 \pm 1.2$ & $74.9 \pm 2$ & $72.4 \pm 1.2$ \\
SDNN, msec & $54.3 \pm 11.8$ & $32.9 \pm 4.4$ & $63.1 \pm 20.0$ \\
RMSSD, msec & $33.0 \pm 6.9$ & $20.9 \pm 4.1$ & $35.1 \pm 10.9$ \\
LF, msec ${ }^{2}$ & $293.4 \pm 83.6$ & $276.7 \pm 85$ & $310.2 \pm 82.3$ \\
HF, msec & $274.1 \pm 100.4$ & $252.7 \pm 98$ & $295.5 \pm 125.4$ \\
Total, msec ${ }^{2}$ & $1189.9 \pm 324.9$ & $1166.5 \pm 324.6$ & $1213.4 \pm 325.3$ \\
LF/HF & $3.21 \pm 0.9$ & $2.5 \pm 0.5$ & $3.92 \pm 1.4$ \\
\hline
\end{tabular}

After the investigation the above mentioned parameters for each studied drug were calculated. In group 1 (with ivabradine) there was a change of the vital HRV parameters between investigations 1 and 2 and in group 2 those between 3 and 4 were summarized (Table 3 ). Accordingly, in group 2 (with metoprolol) there were changes of parameters between investigations 3 and 4, and in group 1 the changes between the $1^{\text {st }}$ and the $2^{\text {nd }}$ ones were revealed.

As a result, HR decreased significantly in the study with ivabradine, namely from 72 to 65 beats $/ \mathrm{min}(\mathrm{Cl} 78-68, \mathrm{p}=0.001)$ and with metoprolol it went down from 72 to 65 beats $/ \mathrm{min}(\mathrm{Cl}$ $70-64, p=0.001$, Figure 2 ). Thus, the drugs showed comparable negative chronotropic effects. In particular, ivabradine, as well as the metoprolol, did not reduce SBP and DBP $(p=0.114$ and $p=0.577$ for ivabradine and $p=0.129$ and $p=0.196$ for metoprolol). As in ivabradine, so in metoprolol effect $(\Delta / \mathrm{min})$ increased with HR rise (Figure 3). There was similar decrease in HR in both groups ( $p=0.400$ between groups), and no change in $B P$ ( $p=0.114$ for SBP and $p=0.796$ for DBP between groups). Such results enabled the comparison of both drugs' impact on the state of autonomic nervous system of heart rate regulation defined by the HRV. As it is presented in Figure 3, after the tests the effect $(\Delta / \mathrm{min})$ of both drugs increased with $\mathrm{HR}$ rise.

LF spectral power reflects the tone of parasympathetic nervous system [4].

Ivabradine reduced significantly LF domains of HRV in absolute values $\left(\Delta=-53.0 \mathrm{msec}^{2}, \mathrm{p}=0.020\right)$, but not in relative $(\Delta=-2.2 \%, \mathrm{p}=0.614)$. Metoprolol had greater effect, reducing both absolute and relative value of HF domain $\left(\Delta=-131.5 \mathrm{msec}^{2}\right.$, $\mathrm{p}=0.011$ and $-15.9 \%, \mathrm{p}=0.006$ ). The comparison of HF domain absolute values affirmed the above-mentioned changes, i.e., metoprolol induced greater decrease ( $p=0.019$, Table 3 ).

The total power parameter reflects adaptation potential of the heart. TP had tendency to decrease in ivabradine $(\Delta=143$ $\left.\mathrm{msec}^{2}, \mathrm{p}=0.424\right)$, and it was downregulated significally by metoprolol ( $\left.\Delta=380 \mathrm{msec}^{2}, \mathrm{p}=0.006\right)$.

The ratio $L F / H F$ showed the tendency to increase in ivabradine group ( $\left.\Delta=0.25 \mathrm{msec}^{2}, \mathrm{p}=0.338\right)$, and to decrease in metoprolol group ( $\Delta=-1.18 \mathrm{msec}^{2}, \mathrm{p}=0.332$ ), reflecting change in symphathic/parasymphathic status under the drugs influence.

The remaining parameters SDNN, RMSSD are used traditionally for prolonged ECG analysis ( $24 \mathrm{~h}$ or $48 \mathrm{~h}$ recording). Also, metoprolol and ivabradine showed expectedly insig-nificant trend to decrease them $(p>0.05)$.

\section{Discussion}

The modulation of the elevated $H R$ and the use of $B B$ are the cornerstone of $C A D$ and $A P$ treatment [11]. BB, especially highly selective ones, are the "gold standard" of rhythm-controlled therapy [17]. At the same time, BB have several contraindications, such as AV-block, bronchial asthma, peripheral arterial disease, etc. Furthermore, in some cases, for example in hypotension or resistive tachycardia the use of other pulse-downregulating drugs is required. Some studies such as REACH (The REduction of Atherothrombosis for Continued Health) showed no advantage of $\mathrm{BB}$ over ivabradine the on the primary endpoints in patients with $\mathrm{AP}$ in the absence of past myocardial infarction [16]. Taking into account the widespreading use of $\mathrm{I}_{\mathrm{f}}$-blocker ivabradine in the clinical practice, its significant antianginal effect and minimal number of side effects $[9,19]$, the choice 
Zagidullin et al. Cardiovascular System 2014,

http://www.hoajonline.com/journals/pdf/2052-4358-2-9.pdf

Table 3. Comparison of Met and Iva effect on HR, BP and HRV.

\begin{tabular}{|c|c|c|c|c|c|c|c|}
\hline Parameter & Baseline & Ivabradine & $\mathrm{p} \Delta$ Iva & Baseline & Metoprolol & $\begin{array}{l}\mathrm{p} \Delta \\
\text { Metoprolol }\end{array}$ & $\begin{array}{l}\mathrm{p} \Delta_{\text {individual }} \text { Ivabradine- } \\
\text { Metoprolol }\end{array}$ \\
\hline SBP, mm Hg & $130(120 ; 140)$ & $130(120 ; 140)$ & 0.114 & $130(120 ; 140)$ & $130(120 ; 130)$ & 0.129 & 0.134 \\
\hline DBP, mm Hg & $80(80 ; 90)$ & $80(80 ; 80)$ & 0.577 & $80(80 ; 90)$ & $80(80 ; 80)$ & 0.196 & 0.796 \\
\hline $\mathrm{HR}$, beat/min & $72(68 ; 78)$ & $65(64 ; 70)$ & 0.001 & $72(68 ; 76)$ & $65(64 ; 70)$ & 0.001 & 0.429 \\
\hline $\mathrm{SDNN}, \mathrm{ms}$ & $28.1(18.9 ; 40.2)$ & $24.5(17.0 ; 37.5)$ & 0.581 & $30.6(18.8 ; 63.2)$ & $23.7(20.4 ; 41.8)$ & 0.155 & 0.155 \\
\hline RMSSD, ms & $17.8(10.0 ; 29.5)$ & $16.1(8.1 ; 29.5)$ & 0.371 & $22.6(9.2 ; 42.1)$ & $16.4(12.0 ; 22.6)$ & 0.140 & 0.556 \\
\hline Ptotal, $\mathrm{ms}^{2}$ & $595(326 ; 1028)$ & $452(251 ; 983.5)$ & 0.424 & $926(366 ; 1322)$ & $546(262 ; 554)$ & 0.006 & 0.015 \\
\hline $\mathrm{LF}, \mathrm{ms}^{2}$ & $145.0(60.5 ; 216.0)$ & $93.0(49.5 ; 187.0)$ & 0.020 & $220.0(89.0 ; 796.2)$ & $88.5(52.5 ; 221.5)$ & 0.011 & 0.019 \\
\hline $\mathrm{HF}, \mathrm{ms}^{2}$ & $86.0(27.0 ; 354.0)$ & $134.5(16.0 ; 485.0)$ & 0.808 & $105.0(39.0 ; 443.5)$ & $77.5(26.0 ; 148.5)$ & 0.215 & 0.423 \\
\hline LF\% & $60.9(51.7 ; 73.8)$ & $63.1(49.9 ; 72.1)$ & 0.614 & $72.6(62.0 ; 78.5)$ & $56.7(49.6 ; 70.1)$ & 0.019 & 0.056 \\
\hline $\mathrm{LF} / \mathrm{HF}$ & $1.92(1.03 ; 4.28)$ & $2.17(1.39 ; 4.49)$ & 0.338 & $2.62(1.96 ; 2.96)$ & $1.44(0.98 ; 2.24)$ & 0.332 & 0.124 \\
\hline
\end{tabular}

P.s. Data are presented as Median (25\% quartile; $75 \%$ quartile). HR: Heart rate; SBP: Systolic blood pressure; DBP: Diastolic blood pressure; SDNN: Standard deviation of NN intervals; square root of the mean squared differences of successive normal NN intervals-RMSSD; LF: Low frequency; HF: High frequency spectral power and the ratio of waves of low and high frequency-LF/HF

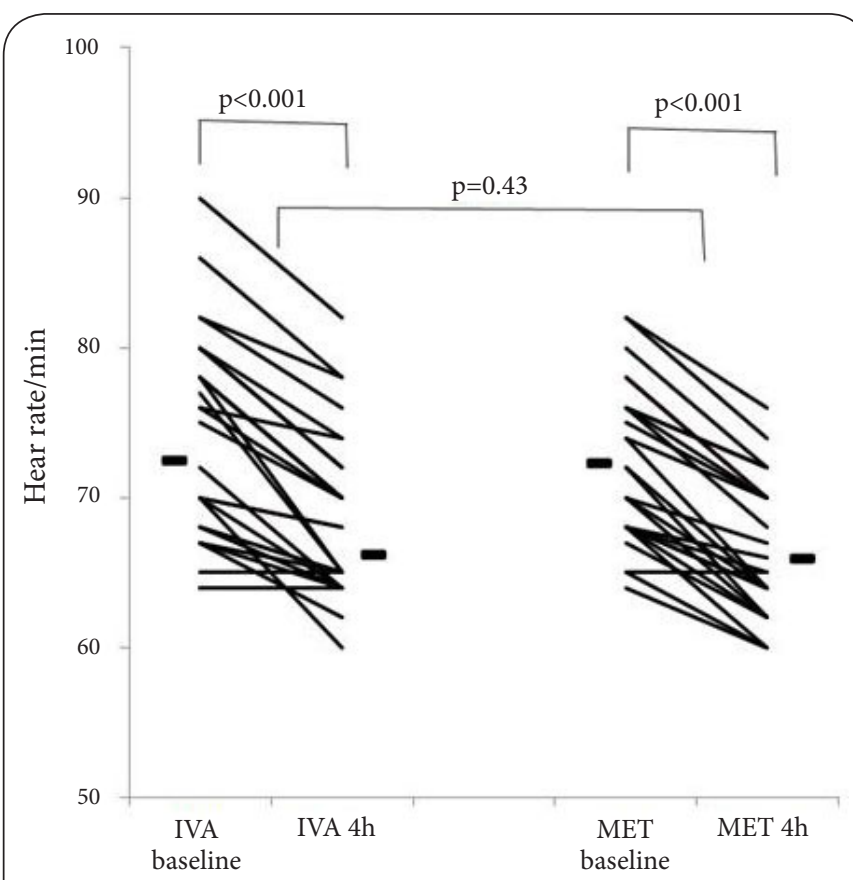

Figure 2. Individual heart rate changes after ivabradine (IVA) $5 \mathrm{mg}$ and metoprolol tartrate (MET) $50 \mathrm{mg}$ exposition.

of rhythm-controlling drug is relevant. Further comparison of these drug classes should be considered not only by ratereducing and antianginal effects, but also by the impact on HRV. HRV is generally accepted as an indicator of sympathetic/ parasympathetic tones balance and predictor of unfavorable cardiovascular and other events. Positive impact of BB on $\mathrm{HRV}$ on reducing sympathetic tone of nervous system and increasing of parasympathetic was repeatedly shown. In particular, Wennerblom B. et al., (1998) [20] showed that

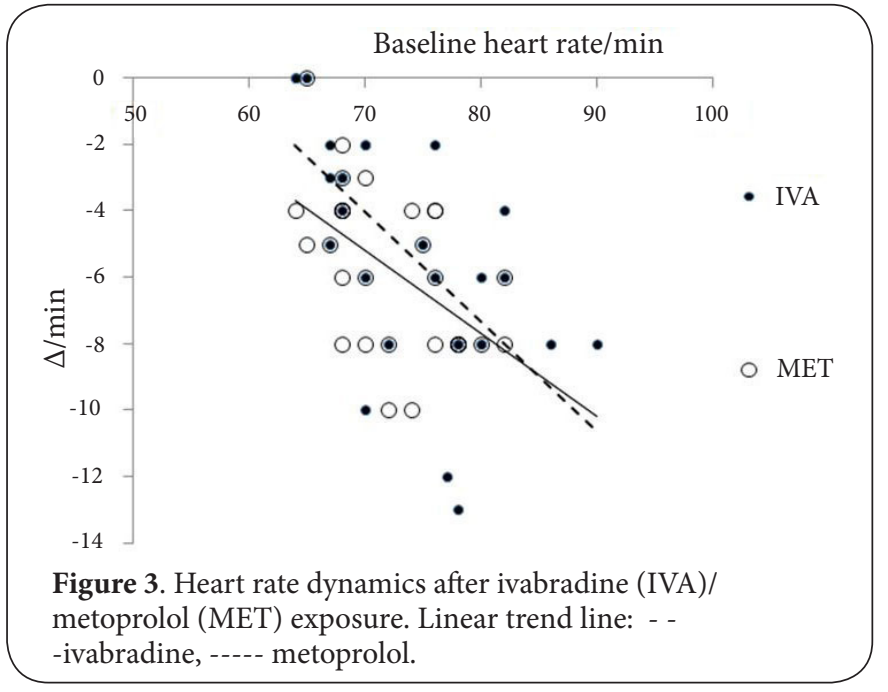

metoprolothe in the dosage of $100 \mathrm{mg}$ per day reduced the tone of the sympathetic nervous system, improved prognosis for the disease in patients with AP with II-III NYHA functional class. In the study of Targoński R. et al., (2009) [21] it has been revealed that the evening dose of $\mathrm{BB}$ was better for their impact on the autonomic balance than the morning one.

At the same time, there are only few small studies on impact of $\mathrm{I}_{\mathrm{f}}$-blocker ivabradine on HRV in compare with $\mathrm{BB}$. We conducted open-labeled, randomized, controlled trial with crossover design and acute pharmacological test to evaluate the effect of the $I_{\mathrm{f}}$-blocker ivabradine and BB metoprololtartrate on the HRV in 33 patients with angina pectoris. As a result, in the group with ivabradine and metoprolol HR significantly reduced to 7.0 beats/min, i.e., negative chronotropic effect of the both drugs was comparable Ivabradine, as well as metoprolol, did not change SBP and DBP. Both drugs 
decr-eased sympathetic activity by decreasing LF domain but for metoprolol the effect was greater. While for metoprolol such conclusion was expected because of the widely known sympathetic downregulating activity of $\mathrm{BB}$ by reducing positive inotropic and chronotropic effects of catecholamine mediating through b1-b2-adrenergic receptors and adreno-dependent relaxation of vascular smooth muscle cells [22], no data on the direct effect of ivabradine on sympathetic activity have been obtained for ivabradine. In our opinion, the reduction of sympathetic influences on the autonomic regulation of the heart may be associated with a reduction of myocardial ischemia by feedback mechanism (Figure 4).

The additional advantage of ivabradine is the absence of TP

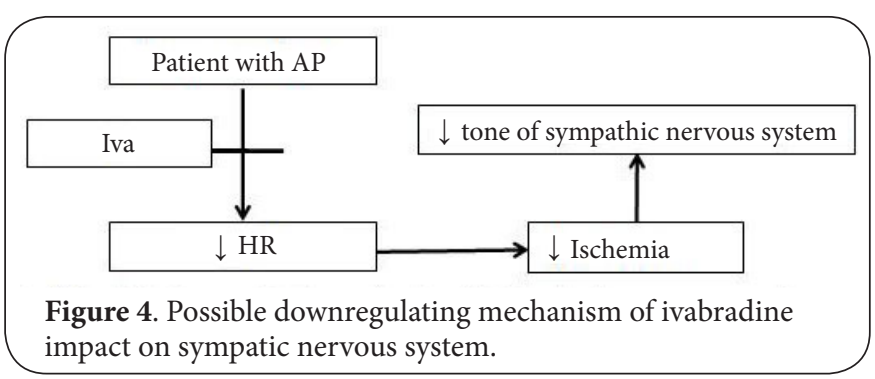

decrease observed in metoprolol treatment, which reflects the adaptation resource of the heart.

Recent randomized clinical trials indicate ivabradine's antianginal effects comparable with BB and some calcium antagonists [23-25]. Ivabradine prolongs diastole more than BB [26], which is critical for myocardial oxygen supply. Having given the presence of specific contraindication to BB (atrioventricular block, bronchial asthma), the additional impact on the vegetative status of HR can support indications for use of ivabradine at stable angina pectoris.

\section{Conclusions}

In prospective, open-labeled, short-term, controlled, crossover with acute pharmacological test design patients with coronary heart disease and angina pectoris having received both metoprolol tartrate and ivabradine 7.5 per os decreased equally heart rate. The effect attenuated with the heart rate upraises.

Both metoprolol tartrate $50 \mathrm{mg}$ and ivabradine $7.5 \mathrm{mg}$ showed a cardioprotective effect on HRV by downregulating LF domain and reducing sympathetic activity (more significant for metoprolol). For ivabradine this fact can be explained by decrease of ischemia by feedback mechanism.

Metoprolol, but not ivabradine decreased the total power parameter of heart rate variability.

\section{Competing interests}

The authors declare that they have no competing interests.

\section{Authors' contributions}

\begin{tabular}{|l|c|c|c|c|}
\hline Authors' contributions & NSZ & RHZ & EOT & SZZ \\
\hline Research concept and design & $\checkmark$ & $\checkmark$ & $\checkmark$ & $\checkmark$ \\
\hline Collection and/or assembly of data & $\checkmark$ & $\checkmark$ & $\checkmark$ & $\checkmark$ \\
\hline Data analysis and interpretation & $\checkmark$ & $\checkmark$ & $\checkmark$ & $\checkmark$ \\
\hline Writing the article & $\checkmark$ & $\checkmark$ & $\checkmark$ & $\checkmark$ \\
\hline Critical revision of the article & $\checkmark$ & $\checkmark$ & $\checkmark$ & $\checkmark$ \\
\hline Final approval of article & $\checkmark$ & $\checkmark$ & $\checkmark$ & $\checkmark$ \\
\hline Statistical analysis & $\checkmark$ & $\checkmark$ & $\checkmark$ & $\checkmark$ \\
\hline
\end{tabular}

Acknowledgement and funding

We thank Svetlana Mishlanova L. Professor, PhD, Head of Language Education Department, Perm State National Research University for English and grammar correction. Study was supported by the grant of President of Russian Federation MD-2459.2014.7 (Zagidullin NS).

Publication history

Editor: Piero Pollesello, Orion Pharma, Finland. Senior Editor: Shiwei Duan, Ningbo University, China. Received: 04-Oct-2014 Final Revised: 07-Nov-2014 Accepted: 18-Nov-2014 Published: 22-Nov-2014

\section{References}

1. Malik M and Camm AJ. Heart rate variability: from facts to fancies. $J \mathrm{Am}$ Coll Cardiol. 1993; 22:566-8. I Article I PubMed

2. Camm AJ, Malik M, Bigger JT, Breithardt G, Cerutti S, Cohen RJ et al. Task Force of The European Society of Cardiology and The North American Society of Pacing and Electrophysiology. Heart rate variability: standards of measurement, physiological interpretation, and clinical use. Eur Heart J. 1996; 17:354e81. I Article

3. Schwartz PJ and Priori SG. Sympathetic nervous system and cardiac arrhythmias. In: Zipes DP, Jalife J, eds. Cardiac Electrophysiology: From Cell to Bedside. Philadelphia, Pa: WB Saunders Co 1990; 330-343.

4. Heart rate variability. Standards of measurement, physiological interpretation, and clinical use. Task Force of the European Society of Cardiology and the North American Society of Pacing and Electrophysiology. Eur Heart J. 1996; 17:354-81. I Article I PubMed

5. Couvreur N, Tissier R, Pons S, Chetboul V, Gouni V, Bruneval P, Mandet $\mathrm{C}$, Pouchelon JL, Berdeaux A and Ghaleh B. Chronic heart rate reduction with ivabradine improves systolic function of the reperfused heart through a dual mechanism involving a direct mechanical effect and a long-term increase in FKBP12/12.6 expression. Eur Heart J. 2010; 31:1529-37. | Article | PubMed Abstract | PubMed Full Text

6. Zyikov YA, Yavelov IS, Averkov OV, Vaulin NA and Grazianskiy N. Anstable angina: Impact of beta-blockers atenolol and metoprolol on heart rate variability. Kardiologiya. 1998; 2:9-15.

7. The Cardiac Insufficiency Bisoprolol Study II (CIBIS-II): a randomised trial. Lancet. 1999; 353:9-13. I Article I PubMed

8. MERIT-HF Investigators. Effect of metoprolol CR/XL in chronic heart failure: metoprolol CR/XL Randomized Intervention Trial in Congestive Heart Failure (MERIT-HF). Lancet. 1999; 353:2001-7. | Article

9. Difrancesco D. Cardiac pacemaker I(f) current and its inhibition by heart rate-reducing agents. Curr Med Res Opin. 2005; 21:1115-22. | Article | PubMed

10. Zagidullin NSh, Gareeva DF, Zagidullin BI, Travnikova EO and Zagidullin SZ. Current opportunities of heart rate regulation in coronary heart disease. Russian Cardiological Journal. 2013; 5:61-65.

11. Fox K, Garcia MA, Ardissino D, Buszman P, Camici PG, Crea F, Daly C, De Backer G, Hjemdahl P, Lopez-Sendon J, Marco J, Morais J, Pepper J, Sechtem U, Simoons M, Thygesen K, Priori SG, Blanc JJ, Budaj A, Camm J, Dean V, Deckers J, Dickstein K, Lekakis J, McGregor K, Metra M, Osterspey A, Tamargo J and Zamorano JL. Guidelines on the management of stable angina pectoris: executive summary: The Task Force on the 
Zagidullin et al. Cardiovascular System 2014,

Management of Stable Angina Pectoris of the European Society of Cardiology. Eur Heart J. 2006; 27:1341-81. | Article | PubMed

12. Fox K, Ford I, Steg PG, Tardif JC, Tendera M and Ferrari R. Rationale, design, and baseline characteristics of the Study assessinG the morbidity-mortality beNefits of the If inhibitor ivabradine in patients with coronarY artery disease (SIGNIFY trial): a randomized, doubleblind, placebo-controlled trial of ivabradine in patients with stable coronary artery disease without clinical heart failure. Am Heart J. 2013; 166:654-661 e6. | Article | PubMed

13. Fox K, Ford I, Steg PG, Tendera M and Ferrari R. Ivabradine for patients with stable coronary artery disease and left-ventricular systolic dysfunction (BEAUTIFUL): a randomised, double-blind, placebocontrolled trial. Lancet. 2008; 372:807-16. | Article | PubMed

14. Swedberg K, Komajda M, Bohm M, Borer JS, Ford I, Dubost-Brama A, Lerebours $G$ and Tavazzi $L$. Ivabradine and outcomes in chronic heart failure (SHIFT): a randomised placebo-controlled study. Lancet. 2010; 376:875-85. | Article | PubMed

15. Belal SAS, Nazarenko EO, Radchenko AO et al. Ivabradine and quality of biofeedback in the loop of paced breathing under the control of heart rate variability parameters in healthy volunteers. Journal of $V . N$. Karazin`KhNU. 2013; 1044:13-16. | Article

16. Joannides R, Moore N, lacob M, Compagnon P, Lerebours G, Menard JF and Thuillez C. Comparative effects of ivabradine, a selective heart rate-lowering agent, and propranolol on systemic and cardiac haemodynamics at rest and during exercise. Br J Clin Pharmacol. 2006; 61:127-37. | Article | PubMed Abstract | PubMed Full Text

17. ESC guidelines on the management of stable coronary artery disease. The Task Force on the management of stable coronary artery disease of the European Society of Cardiology. European Heart Journal. 2013; 34:2949-3003. | Article

18. Bangalore S, Steg G, Deedwania P, Crowley K, Eagle KA, Goto S, Ohman EM, Cannon CP, Smith SC, Zeymer U, Hoffman EB, Messerli FH and Bhatt $\mathrm{DL}$. beta-Blocker use and clinical outcomes in stable outpatients with and without coronary artery disease. JAMA. 2012; 308:1340-9. | Article I PubMed

19. Zagidullin NSh, Michels G and Hoppe UC. Decrease of heart rate in stable angina pectoris: $\boldsymbol{\beta}$-blockers and If-inhibitors. Klinicheskaya Pharmacologiya I Therapia. 2008; 3:1-6.

20. Wennerblom B, Lurje L, Westberg S, Johansson M, Lomsky M, Vahisalo $R$ and Hjalmarson $A$. Effects on heart rate variability of isosorbide-5mononitrate and metoprolol in patients with recent onset of angina pectoris. Cardiology. 1998; 89:87-93. | Article | PubMed

21. Targonski $R$ and Sadowski J. The effect of an evening dose of a longacting beta-blocker on the autonomic tone in patients with congestive heart failure. Kardiol Pol. 2009; 67:963-70. | PubMed

22. Schafers RF, Poller U, Ponicke K, Geissler M, Daul AE, Michel MC and Brodde OE. Influence of adrenoceptor and muscarinic receptor blockade on the cardiovascular effects of exogenous noradrenaline and of endogenous noradrenaline released by infused tyramine. Naunyn Schmiedebergs Arch Pharmacol. 1997; 355:239-49. | Article I PubMed

23. Tardif JC, Ford I, Tendera M, Bourassa MG and Fox K. Efficacy of ivabradine, a new selective I(f) inhibitor, compared with atenolol in patients with chronic stable angina. Eur Heart J. 2005; 26:2529-36. | Article I PubMed

24. Borer JS, Fox K, Jaillon P and Lerebours G. Antianginal and antiischemic effects of ivabradine, an I(f) inhibitor, in stable angina: a randomized, double-blind, multicentered, placebo-controlled trial. Circulation. 2003; 107:817-23. | Article | PubMed

25. Ruzyllo W, Ford I, Tendera $M$ et al. Antianginal and antiischemic effects of the If current inhibitor ivabradine compared to amlodipine as monotherapy in patients with chronic stable angina: a 3-month randomized, controlled, double-blind, multi-center trial. Eur Heart J. 2004; 25:878:138.

26. Colin P, Ghaleh B, Hittinger L, Monnet X, Slama M, Giudicelli JF and Berdeaux A. Differential effects of heart rate reduction and betablockade on left ventricular relaxation during exercise. Am J Physiol Heart Circ Physiol. 2002; 282:H672-9. | Article | PubMed

\section{Citation:}

Zagidullin NS, Zulkarneev RH, Travnikova EO and Zagidullin SZ. Comparison of ivabradine and metoprolol tartrate impact on the heart rate variability in patients with angina pectoris. Cardio Vasc Syst. 2014; 2:9.

http://dx.doi.org/10.7243/2052-4358-2-9 